\section{ELEGANCE COMBINED WITH MAXIMUM HYGIENE}

Saratoga Cabinetry only from Plandent is a beautiful range strongly characterised by the wall configurations to combine elegance with maximum hygiene. The stylish ergonomic wall units look stunning and will certainly add style to your practice and impress your patients.

Made entirely of high quality steel and painted using the Bonderite nanotechnology technique, the result is that the units are available in a wide range of colours with a varied choice in handles, including the notouch option for optimum infection control.

Plandent's specialists will advise you on design and layout to maximise the efficiency of the available space, be it your treatment room, sterilisation centre or hygienist surgery.

Plan for your new cabinets with Plandent and call 0500500322.

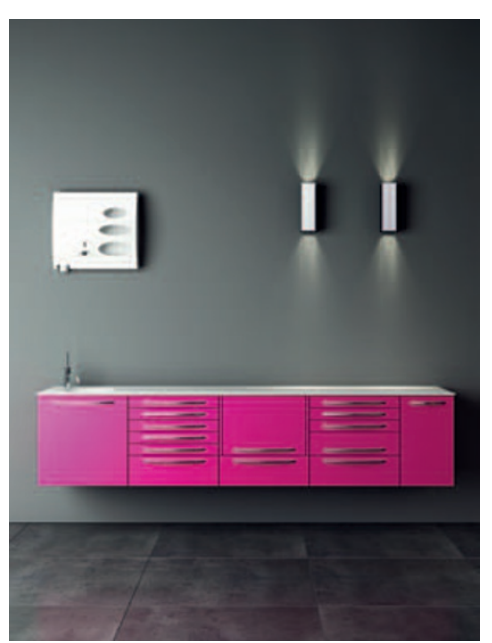

\section{EASY, STRESS-FREE CABINETRY}

For over 35 years, Tavom has distinguished itself as one of the leading providers of bespoke dental and medical cabinetry in the industry.

The team at Tavom understand that every room within a dental practice has a well-defined purpose, and it is important that each of these areas function with optimal efficacy. They also have all the experience and skills to ensure your new practice meets all your specifications, and a range of colours and finishes are available to help you create a design totally unique to you.

Supplied by Tavom UK, all cabinetry is crafted of the most durable materials for maximum longevity, and styles incorporate ergonomics for optimal comfort and aesthetics for both staff and patient alike.

With absolute dedication to first-class customer service, open communication and flexible working times, you can also rely on the team at Tavom UK to make the whole process as easy and stress-free as possible.

For a full catalogue of products, or to find out more, please visit www.tavomuk.com.

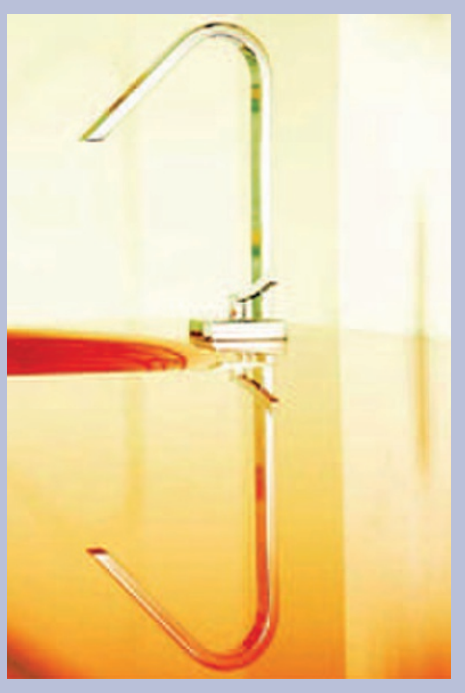

\title{
NEW 3D TOOLS FOR DENTAL LABORATORIES
}

Planmeca Romexis is a comprehensive software suite used by dental professionals for acquiring, viewing and processing $2 \mathrm{D}$ and 3D images. Planmeca now introduces a new Planmeca Romexis 3D Ortho Studio module to the software, bringing innovative 3D tools for orthodontists and dental laboratories. The new module is designed for examination and analysis of digital dental models scanned with Planmeca ProMax 3D X-ray units and for planning orthodontic treatments in 3D.

Dental impressions and plaster casts scanned with the Planmeca ProMax 3D model scanning mode can be analysed in the Planmeca Romexis 3D Ortho Studio module. The module makes dental model analyses easier than ever by offering all the necessary tools for virtual base creation, occlusion examination and versatile teeth and arch measurements.

A staged treatment plan can be established in Planmeca Romexis 3D Ortho Studio by displacing the teeth in a virtual tooth setup, while visualising intersections and contacts. All the applied changes such as tooth movements, interproximal reductions and teeth extractions are summarised in a detailed treatment plan report, which can be easily shared with others.

The Planmeca Romexis 3D Ortho Studio module generates a sequence of digital dental models for each stage of the treatment. The models can be exported in STL format for 3D printing, custom appliance design and manufacturing.

www.planmeca.com

\section{MOVE TOWARDS A PAPERLESS PRACTICE}

Interested in digitising your X-rays and moving towards a paperless practice, but worried about integrating the new technology, if it is compatible with your practice management software and if it is cost effective?

Imaging with PSP plates offers all the flexibility and patient comfort of film, combined with the immediacy and environmental benefits of digital radiography. Use your existing X-ray holders and expose the flexible digital PSP plate. Drop it into the Apixia PSP Scanner and in less than ten seconds the crystal clear digital radiograph appears on your screen. Insert the next exposed plate when ready. Image plates are automatically erased and can be used hundreds of times.

The digital X-rays are attached to the patient's clinical records as the Apixia imaging software links to any practice management software. It can be easily integrated into existing imaging software, so you don't have to learn a new program.

It is small enough for handy chairside use, yet robust enough to be placed in a central location for use by the entire team. www.digitaldental.co.uk 